\title{
Decreased type V collagen expression in human decidual tissues of spontaneous abortion during early pregnancy
}

\author{
M Iwahashi, R Nakano
}

\begin{abstract}
Aim-To provide some insight into the aetiology of spontaneous abortion, the contents of type $V$ collagen was investigated in human decidual tissues in spontaneous abortion and normal pregnancy. Methods-Collagens were extracted from decidual tissues in spontaneous abortion $(n=19)$ and normal pregnancy $(n=25)$. The different types of collagen $\alpha$ chains were separated by sodium dodecyl sulphate-polyacrylamide gel electrophoresis (SDS-PAGE), stained with Coomassie brilliant blue, and measured by densitometry. The relative amounts of the $\alpha 1$ (III) and $\alpha 1(V)$ chains were calculated by dividing the band intensities of the $\alpha 1$ (III) and $\alpha 1$ (V) chains by that of the a1(I) chain.

Results-The ratio of the $\alpha 1(\mathrm{~V})$ chain to that of the $\alpha 1$ (I) chain in decidual tissues in spontaneous abortion was significantly lower than that found in normal pregnancy $(p<0.05)$.

Conclusions-These results suggest that type $V$ collagen might play an important role in the maintenance of pregnancy and that decreased expression of this collagen could be associated with spontaneous abortion.

(F Clin Pathol 1998;51:44-46)
\end{abstract}

Keywords: spontaneous abortion; decidua; collagen type $\mathrm{V}$

Spontaneous abortion is the most common complication of pregnancy. Although the exact mechanisms responsible for abortion are not always apparent, it has been proposed that various maternal or fetal factors, such as chromosomal abnormalities, might induce the interruption of pregnancy. Placental and decidual histology has been investigated previously in relation to the chromosome number after spontaneous abortion in early pregnancy. ${ }^{12}$

The extracellular matrix is thought to play an important role in the stability of tissues and in regulating the growth and differentiation of cells. ${ }^{34}$ Synthesis, accumulation, and catabolism of the extracellular matrix are involved in wound healing and in the initiation and progression of numerous diseases. ${ }^{5}$ The extracellular matrix, which is composed of collagen, laminin, fibronectin, and proteoglycans in the human endometrium and decidua, has been studied in early pregnancy, ${ }^{6-9}$ but the alterations in decidual extracellular matrix in failed pregnancy are not fully understood. Among the various collagens, type $\mathrm{V}$ collagen was described originally as a component of chorionic and amniotic membranes. ${ }^{10}$ It is thought to play a major role in maintaining a barrier against pathogens and inflammatory cells, and in preventing the loss of amniotic fluid. ${ }^{11}$ In addition, this collagen has been shown to mediate the behaviour of cells including their attachment, spread, proliferation, and morphogenesis. ${ }^{12-15}$ In the present study, we investigated the decidual contents of type $\mathrm{V}$ collagen after spontaneous abortion in early pregnancy, using sodium dodecyl sulphatepolyacrylamide gel electrophoresis (SDSPAGE), and compared the results with those obtained in normal pregnancy.

\section{Methods}

This project was approved by the Committee on Investigations Involving Human Subjects of Wakayama Medical College. Informed consent was obtained from each subject after the purpose and nature of the study had been explained fully.

\section{TISSUES}

Normal decidual tissues were obtained from 25 women aged $20-38$ years during early pregnancy (7-12 weeks) by dilatation and curettage for termination of pregnancy and were frozen immediately in liquid nitrogen. Decidual tissues from 19 women aged 19-41 years were also obtained by dilatation and curettage after spontaneous abortions at 7-12 weeks of gestation. The details of the subjects with spontaneous abortion are: four cases of luteal phase defect, four cases of septic abortion, four cases of blighted ovum, two cases of systemic lupus erythematosus, two cases of anticardiolipin antibody positivity, one case of 18 trisomy in the abortus, and one case of uncontrolled diabetes mellitus. We excluded specimens containing villous tissues or necrotic decidual tissue from analysis by examination of haematoxylin and eosin stained frozen sections. Gestational age was determined by the date of the last menstrual period and by ultrasonographic measurements performed in early pregnancy.

\section{SDS-PAGE OF PEPSIN SOLUBILISED COLLAGENS}

FROM THE HUMAN DECIDUA

Minced samples of human endometrium were washed overnight in cold distilled water and freed of blood. Tissues were homogenised with a Polytron homogeniser in 50 volumes of $0.5 \mathrm{M}$ acetic acid that contained $1 \mathrm{mg} / \mathrm{ml}$
Accepted for publication 10 October 1997 


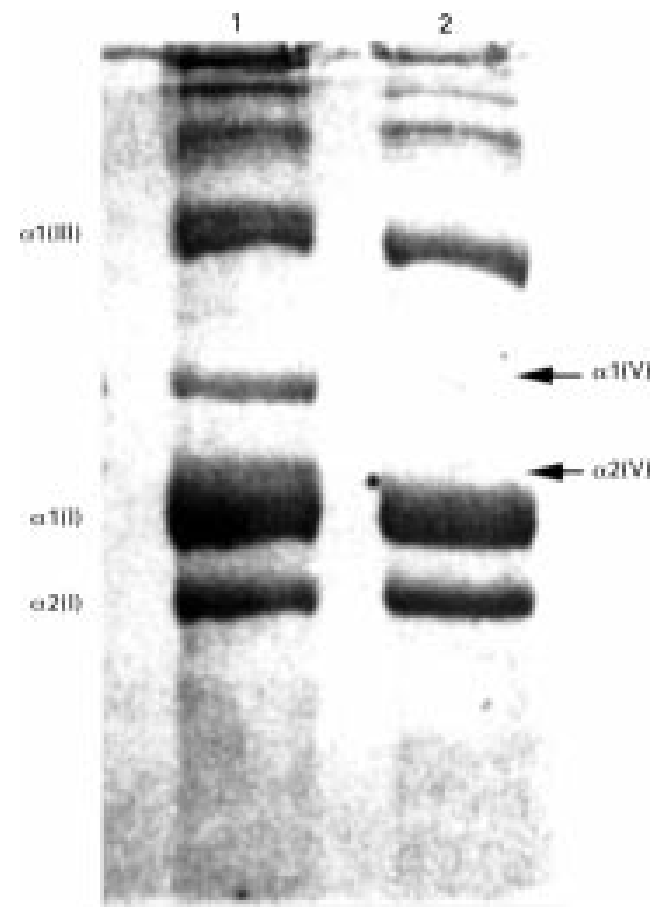

Figure 1 SDS-PAGE of pepsin solubilised collagens of decidual tissues in normal pregnancy (lane 1) and spontaneous abortion (lane 2) (a case of blighted ovum). Samples of heat denatured collagen $(5 \mu \mathrm{g})$ were subjected to electrophoresis on a slab gel for one hour. After reduction in situ with $\beta$ mercaptoethanol for 30 minutes, electrophoresis was resumed for one hour.

pepsin (Sigma Chemical Co, St Louis, Missouri, USA). Collagens were extracted with constant stirring for 24 hours at $4^{\circ} \mathrm{C}$. The solutions were centrifuged at $39000 \times g$ for one hour at $4^{\circ} \mathrm{C}$. Collagens were re-extracted from the pellets under the same conditions for 48 hours. The supernatants were then combined and collagens were precipitated by the addition of $4.0 \mathrm{M} \mathrm{NaCl}$ to a final concentration of $2.0 \mathrm{M}$. The precipitate was dissolved in $0.5 \mathrm{M}$ acetic acid and dialysed against $0.02 \mathrm{M}$ $\mathrm{Na}_{2} \mathrm{HPO}_{4}$. Precipitated collagens were redissolved in $0.5 \mathrm{M}$ acetic acid, dialysed exhaustively against $0.05 \mathrm{M}$ acetic acid, and finally lyophilised. The solubility of the tissue collagen from each endometrial sample was estimated by comparing the hydroxyproline content of the initial homogenate with that of the final solution of collagen. ${ }^{16}$ Estimation of the relative abundance of the $\alpha 1$ (III) and $\alpha 1(\mathrm{~V})$ chains was performed by interrupted gel electrophoresis. ${ }^{17}$ Electrophoresis was performed in an $8 \%$ polyacrylamide gel slab (Sigma Chemical Co). The gel and electrode buffers were $0.1 \mathrm{M}$ phosphate buffer, $\mathrm{pH} 7.2$, containing $0.1 \%$ SDS (Nacalai Tesque Inc, Kyoto, Japan), as described previously. ${ }^{16}$ Lyophilised samples of

Table 1 Relative abundance of the a1(III) and a1(V) chains of collagen compared with the 1 (I) chain in the decidual tissues obtained from normal pregnancy and spontaneous abortion

\begin{tabular}{llll}
\hline & & \multicolumn{2}{l}{ Relative ratio of collagen a chain } \\
\cline { 3 - 4 } & Patients $(n)$ & $\alpha 1(I I I) / a 1(I)$ & $\alpha 1(V) / a 1(I)$ \\
\hline Normal pregnancy & 25 & $0.43(0.06)$ & $0.147(0.010)$ \\
Spontaneous abortion & 19 & $0.37(0.04)$ & $0.061(0.011)^{\star}$ \\
\hline
\end{tabular}

Data are means (SEM).

${ }^{\star} \mathrm{p}<0.05$. collagens and type $\mathrm{V}$ collagen were dissolved at a concentration of $0.2 \mathrm{mg} / \mathrm{ml}$ and denatured by heating in gel buffer containing $1 \%$ SDS at $60^{\circ} \mathrm{C}$ for 30 minutes. Aliquots of $25 \mu \mathrm{l}$ of denatured collagens were applied to the gel and subjected to electrophoresis at $80 \mathrm{~mA}$. After 1.5 hours the current was switched off and sample wells were filled with $20 \% \beta$ mercaptoethanol (Wako Chemical Co, Osaka, Japan), which was allowed to diffuse into the gel for one hour to cleave intramolecular disulphide bonds of type III collagen, $\left[(\alpha 1(\mathrm{III})]_{3}\right.$. Subsequently, electrophoresis was resumed and allowed to continue for another hour. Each collagen $\alpha$ chain was stained with Coomassie brilliant blue (Sigma Chemical Co) and quantitated by densitometry. The relative amounts of the $\alpha 1$ (III) and $\alpha 1(\mathrm{~V})$ chains were calculated by dividing the intensities of the $\alpha 1$ (III) and $\alpha 1(\mathrm{~V})$ bands by that of the $\alpha 1$ (I) band.

STATISTICAL ANALYSIS

The ratios of the $\alpha 1$ (III) to $\alpha 1$ (I) chains and the $\alpha 1(\mathrm{~V})$ to $\alpha 1(\mathrm{I})$ chains, as estimated by densitometry, were expressed as mean (SEM). Mean values were compared by the Student's $t$ test or analysis of variance, using a StatView software program on a Macintosh computer. Two tailed $\mathrm{p}$ values less than 0.05 were considered to be statistically significant.

\section{Results}

Although the relative amounts of $\alpha 1$ (I) and $\alpha 1$ (III) were almost similar in the decidua obtained from normal pregnancy and spontaneous abortion, those of $\alpha 1(\mathrm{~V})$ and $\alpha 2(\mathrm{~V})$ were markedly decreased in the decidua from cases of spontaneous abortion (fig 1). The ratios of the band intensities of the $\alpha 1$ (III) to $\alpha 1$ (I) chains and the $\alpha 1(\mathrm{~V})$ to $\alpha 1(\mathrm{I})$ chains were expressed as mean (SEM) in the decidua of normal pregnancy and spontaneous abortion, respectively (table 1). The ratio of the band intensities of $\alpha 1$ (III) to $\alpha 1$ (I) in the decidua was not significantly different between normal pregnancy and spontaneous abortion. However, the ratio of the band intensities of $\alpha 1(\mathrm{~V})$ to $\alpha 1$ (I) in the decidua in spontaneous abortion was significantly lower than in normal pregnancy $(p<0.05)$.

\section{Discussion}

In the present study, we used SDS-PAGE to investigate the amount of type $\mathrm{V}$ collagen in decidual tissues after spontaneous abortion and compared the results with those obtained in normal pregnancy. We were able to solubilise $70-85 \%$ of the collagen in human decidual tissues, as measured by reference to levels of hydroxyproline (data not shown). Therefore, it was postulated that the extracted collagen might reflect accurately the entire complement of collagen in the tissues. Previously, we have reported increased relative amounts of type $\mathrm{V}$ collagen in the human endometrium during the process of decidualisation. ${ }^{18}$ The reduced decidual concentration of type $\mathrm{V}$ collagen in spontaneous abortion suggests at least two possible mechanisms for regulation of the turnover of this collagen. Firstly, the synthesis 
of type $\mathrm{V}$ collagen by decidual cells might be reduced at the gene level in spontaneous abortion. Secondly, the degradation of decidual type $\mathrm{V}$ collagen might be intensified in spontaneous abortion. Although the interstitial collagens, such as type I and III collagen, and laminin showed normal concentrations in the decidual tissues obtained from patients with spontaneous abortion, type IV collagen concentrations were very low. ${ }^{19}$ This finding suggests that type IV collagenase (gelatinase A and B) activity might be increased in the decidual tissues of patients with spontaneous abortion. Gelatinase A and B are thought to be produced by the decidual cells themselves ${ }^{20}$ or, in cases of infectious spontaneous abortion, by bacteria. In additon, these gelatinases could degrade type $\mathrm{V}$ collagen. ${ }^{21}$ In addition, it is possible that decreased decidual synthesis and increased degradation of type $\mathrm{V}$ collagen occur simultaneously in spontaneous abortion.

Type $\mathrm{V}$ collagen has the ability to bind to insulin $^{22}$ and to heparin/heparan sulphate, ${ }^{23}$ apparently with higher affinity than collagen types I, II, III, IV, or VI, fibronectin, or laminin. Recent studies have indicated that insulin bound to type $\mathrm{V}$ collagen retains mitogenic activity $^{22}$ and that heparin/heparan sulphate modulates the biological activities of vascular endothelial cell growth factor ${ }^{24}$ and basic fibroblast growth factor. ${ }^{25} 26$ These findings suggest that type $\mathrm{V}$ collagen might be important in the compartmentalisation, storage, stabilisation, and modulation of the activities of various growth factors. Because type $\mathrm{V}$ collagen also binds to thrombospondin, ${ }^{27}$ the interactions of this collagen with thrombospondin and heparin/heparan sulphate may be important in the assembly of the extracellular matrix and in the regulation of its biological functions. Therefore, it is suggested that an increased relative concentration of $\alpha 1(\mathrm{~V})$ or type V collagen in the decidua might provide a biochemical basis for functional regulation of the decidual cells. It has also been postulated that trophoblast invasion might be modulated by interactions between the extracellular matrix receptors on the surface of trophoblast cells and the corresponding ligands. ${ }^{28-30}$ Thus, a reduction of type $\mathrm{V}$ collagen in the decidua might result in reduced attachment and migration of trophoblast cells or in disruption of the junctions between decidual cells.

Therefore, it is possible that type $\mathrm{V}$ collagen is associated with the nutrition of trophoblastic and endometrial cells, and that a reduced concentration of this collagen induces metabolic abnormalities in the conceptus.

This study provides some clues to understanding the pathophysiology of failed pregnancy in terms of extracellular matrix metabolism. Further work is needed to elucidate the mechanisms regulating the decidual expression of genes for other types of collagen in normal pregnancy and spontaneous abortion.

1 Honore L, Dill FJ, Poland BJ. Placental morphology in spontaneous human abortuses with normal and abnormal spontaneous human abortuses with norm
karyotypes. Teratology 1976;14:151-66.

2 Salafia C, Maier D, Vogel C, Pezzullo J, Burns J, Silberman

L. Placental and decidual histology in spontaneous abortion: detailed description and correlations with chromosome number. Obstet Gynecol 1993;82:295-303.

3 Lin CQ, Bissell MJ. Multi-faceted regulation of cell differentiation by extracellular matrix. FASEB f 1993;7:737-43.

4 Madri JA, Basson MD. Extracellular matrix-cell interactions: dynamic modulators of cell, tissue and organism structure and function. Lab Invest 1992;66:519-21.

5 Haralson MA. Extracellular matrix and growth factors: an integrated interplay controlling tissue repair and progression to disease. Lab Invest 1993;69:369-72.

6 Aplin JD, Charlton AK, Ayad S. An immunohistochemical study of human endometrial extracellular matrix during the menstrual cycle and the first trimester of pregnancy. Cell Tissue Res 1988;253:231-40.

7 Rodgers WH, Matrisian LM, Giudice LC, Dsupin B, Cannon P, Svitek C, et al. Patterns of matrix metalloproteinase expression in cycling endometrium imply differential funcexpression in cycling endometrium imply differential func1994;94:946-53.

8 Burrows TD, King A, Smith SK, Loke YW. Human trophoblast adhesion to matrix proteins: inhibition and signal transduction. Hum Reprod 1995;10:2489-500.

9 Sueoka K, Shiokawa S, Miyazaki T, Kuji N, Tanaka M, Yoshimura Y. Integrins and reproductive physiology: expression and modulation in fertilization, embryogenesis, and implantation. Fertil Steril 1997;67:799-811.

10 Burgeson RE, El Adri FA, Kaitila II, Hollister DW. Fetal membrane collagens: identification of two new collagen alpha chains. Proc Natl Acad Sci USA 1976;73:2379-83.

11 Modesti A, Kalebic T, Scarpa S, Togo S, Grotenclorst G, Liottaq LA, et al. Type V collagen in human amnion is a 12-nm fibrillar component of the pericellular interstitium. Eur 7 Cell Biol 1984;35:246-55.

12 Fukuda K, Koshihara Y, Oda H, Ohyama M, Ooyama T. Type V collagen selectively inhibits human endothelial cell proliferation. Biochem Biophys Res Commun 1988;151: $1060-8$

13 Hashimoto K, Hatai M, Yaoi Y. Inhibition of cell adhesion by type V collagen. Cell Struct Funct 1991;16:391-97.

14 Hatai M, Hashi H, Kato I, Yaoi Y. Inhibition of cell adhesion by proteolytic fragments of type V collagen. Cell Struct Funct 1993;18:53-60.

15 Sakata N, Jimi S, Takebayashi S, Marques MA. Type V collagen represses the attachment, spread and growth of porcine vascular smooth muscle cells in vivo. Exp Mol Pathol 1992;56:20-36

16 Laemmli UK. Cleavage of structural proteins during the assembly of the head of bacteriophage T4. Nature 1970;227:680-5.

17 Sykes B, Puddle B, Francis M, Smith R. The estimation of two collagens from human dermis by interrupted gel electrophoresis. Biochem Biophys Res Commun 1976;72:1472-80.

18 Iwahashi M, Muragaki Y, Ooshima A, Nakano R. Alterations in distribution and composition of the extracellular matrix during decidualization of the human endometrium. f Reprod Fertil 1996;108:147-55.

19 Iwahashi M, Muragaki Y,Ooshima A, Nakano R. Decreased type IV collagen expression by human decidual tissues in spontaneous abortion. 7 Clin Endocrinol Metab 1996;81: 2925-9.

20 Autio-Harmainen H, Hurskainen T, Niskassri K, Höyhyä $M$, Tryggvason K. Simultaneous expression of 70kilodalton type IV collagenase and type IV collagen $\alpha 1$ (IV) chain genes by cells of early human placenta and gestational endometrium. Lab Invest 1992;67:191-200.

21 Hibbs MS, Hoidal JR, Kang AH. Expression of a metalloproteinase that degrades native type $\mathrm{V}$ collagen and denatured collagen by cultured human alveolar macrophages. F Clin Invest 1987;80;1644-50.

22 Yaoi Y, Hashimoto K, Takahara K, Kato I. Insulin binds to type V collagen with retention of mitogenic activity. Exp Cell Res 1991;194:180-5.

23 Richard GL, Agneta H, Jeffrey DE, Steffen G, Magnus H. Binding of heparan sulfate to type V collagen. $\mathrm{F}$ Biol Chem 1989;264:7950-6.

24 Lobb RR, Harper JW, Fett JW. Purification of heparinbinding growth factors. Anal Biochem 1986;154:1-14.

25 Thornton SC, Mueller SN, Levine EM. Human endothelial cells: use of heparin in cloning and long-term serial cultivation. Science 1983;222:623-5.

26 Schreiber AB, Kenny J, Koalski WJ, Friesel R, Mehlman T, Maciag T. Interaction of endothelial cell growth factor with heparin: characterization by receptor and antibody recognition. Proc Natl Acad Sci USA 1985;82:6138-42.

27 Mumby SM, Rauji GJ, Bornstein P. Interactions of thrombospondins with extracellular matrix proteins: selective binding to type V collagen. 7 Cell Biol 1984;98:646-52.

28 Armant DR, Kaplan HA, Lennarz WJ. Fibronectin and laminin promote in vitro attachment and outgrowth of mouse blastocysts. Dev Biol 1986;116:519-23.

29 Korhonen M, Ylanne J, Laitinen L, Cooper HM, Quaranta V, Virtanen I. Distribution of the $\alpha_{1}-\alpha_{6}$ integrin subunits in human developing and term placenta. Lab Invest 1991;65: 347-56.

30 Damsky $\mathrm{CH}$, Fitzgerald ML, Fisher SJ. Distribution patterns of extracellular matrix components and adhesion receptors are intricately modulated during first trimester cytotrophoblast differentiation along the invasive pathway, in vitro. $\mathcal{F}$ Clin Invest 1992;89:210-22. 